\title{
How the Individualized Learning Model is Perceived When Being Implemented by EFL Teachers: a Study at an English Language centre in Can Tho City
}

\author{
Hai Ngo, Ngoc Hua Thanh Le and Lanh Le
}

Faculty of Linguistics and Literature, Tay Do University, Can Tho City, Viet Nam

\begin{abstract}
The individualized learning model has been administered in some English centers as another choice of learning model to help learners with their busyness and flexible learning schedule in Can Tho city. The aim of this descriptive study is two-fold: (1) to find out the teachers' perception of the implementation of the individualized learning model; (2) to investigate the benefits and difficulties teachers face when they implement the individualized learning model in their classrooms. This is a descriptive research. The result shows that the teachers' perceptions of the implementation of the individualized learning was high although the level of perceptions was not high. Consequently, they understood the individualized learning quite well and revealed that there were four main advantages and two disadvantages from implementing the individualized learning. The results contribute a better understanding of the teachers' perceptions of implementing the individualized learning model in the Mekong Delta and provide some valuable data for further research that relates to such learning model in the region.

Key words: the individualized learning, teachers' perceptions, implementation
\end{abstract}

\section{Introduction}

It is truth that life is about priorities. Teaching and learning English language in classroom model which learners have to follow a fixed schedule strictly has applied in Vietnam for a long time. It is controversial whether this classroom model reveals disadvantages. Due to the hustle and bustle life, if plans unexpectedly change or an emergency comes up, the learner may miss an important lesson or lose their attendance grade. In addition, not all learners perceive objects and phenomena in the same way. Those who gets problems with learning pace may need to slow down or revise the lesson a few times while others can quicken the learning process. The inflexibility of the classroom learning has made it difficult to maintain the existing and there should be major changes in its curricula and teaching-learning model.

In the Vietnamese context, the individualized learning model has been implemented in some English centers in order to help learners with their busyness and flexible learning schedule. According to Meyer (2008) the review of the individualized learning model highlighted some evidences of profits to learners not only in facilitating learner-centered education and can be used with all levels of learners but also improving motivation and better confidence. In the individualized learning, learners can arrange their own learning schedule and follow their own learning pace. Lesson content, teaching method, and learning pace are determined by the abilities, interests, and needs of each learner.

Since the individualized learning has been implemented in English centers, new perceptions among teachers have been emerged. These perceptions are not independent of one another but support interactively and might also impact processes of knowledge sharing between teachers and the learners. Concerning the personal teaching context, the researcher looks over the issues related to teachers' perceptions of implementing the individualized learning model in teaching and learning English and would like to know if there are any inconsistencies between what teachers are aware of the implementation of the individualized learning model and their practices in daily teaching context.

The research is carried out to answer these following questions:

1. What are the teachers' perceptions of the implementation of the individualized learning model?

2. What are the advantages and disadvantages the teachers face when they implement the individualized learning model in their classrooms? 


\section{Literature Review}

Bray \& McClaskey (2012) claimed that personalized learning means instruction is paced to learning needs, tailored to learning preferences, and tailored to the specific interests of different learners. Meanwhile, individualized learning means instruction is paced to the learning needs of different learners. Learning goals are the same for all learners, but they can progress through the material at different speeds according to their learning needs. In an environment that is fully personalized, the learning objectives and content as well as the method and pace may all vary. Therefore, personalization encompasses differentiation and individualization and these terms are often used interchangeably.

Meanwhile,Frunză and Petre (2015) stated that individualization of education is one of the key factors that are able to stabilize high quality of education. The individualized learning presupposes creating conditions for educational process that is paced to the learning needs of different learners. Individual learner can progress through the material at different speed according to their individual learning needs and aptitudes. Thus, a learner may take longer to cover a given topic, skip a topic that includes information that he/she already knows or repeat a topic that needed.

Nunan (1993) stated that a learner-centred curriculum comprises similar elements to the traditional teacher-centred-curriculum development, including: planning (including needs analysis, goal and objectives setting), implementation (including methodology and materials development) and evaluation. However, the crucial difference between learner-centred-curriculum and traditional one is that in the former, the curriculum is a collaborative effort between teachers and learners, since learners are closely involved in the decision-making process regarding the content of the curriculum and how it is applied.

A number of studies related to the implementation of the individualized learning and the teachers' perception towards it have been conducted in different contexts.

Baker (1973) outlined what an individualized learning model is and how to implement such a new learning model by considering the problem of unsuccessfulness of the methods, techniques and materials that have been incorporated into existing educational and training systems. As the interest for qualified people to serve in business, industry, government and scholastic organizations expands, so the requirement for educating and training these people becomes greater and greater. So far, various endeavors have been made to create strategies, methods and to get ready for new materials. However, these systems themselves are now inadequate, this incorporation has not been successful. According to Baker, the individualized learning allows the selection of both the curriculum and the manner in which it will be presented for each individual learner. However, it requires almost inordinate amounts of time for staff planning. It also requires budgets which realistically face the problems of well-designed and validated materials; systematically evaluation.

Aiming at finding the efficacy perceptions about the roles of the teacher in the individualized instruction, Karadag (2010) conducted a research with 321 primary school teachers working at 40 primary schools. In his study, a questionnaire, an instrument to collect data, was used to determine teachers' perceptions of efficacy about individualized instruction. The main purpose of the research was to determine the perceptions of teachers about the individualized learning model. The strength of this research was the result. It indicated that primary school teachers perceived themselves as sufficient in terms of planning the learning process and determining the educating exercises. Furthermore, teachers perceived themselves moderately sufficient in terms of establishing objectives for learners; designing suitable teaching material in teachinglearning process; connecting new knowledge with learners' prior knowledge and; constructing the environment which helps students to realize their powerful and weak aspects. On the other hand, teachers perceived themselves insufficient in terms of scheduling teaching-learning process with convenient individual differences and constructing environment with convenient for students who need special education.

Frunză\&Petre (2015) investigated the obstacles in learning's differentiation and individualization on primary school. The purpose of the research is to identify the main sources - obstacle that primary school teachers faced in achieving the differentiation and individualization professional tasks: teaching and evaluation. The group of investigated participants was 60 teachers reported (in the analysis) to three indicators: age, professional grade, professional seniority. They described a prescriptive approach using individualized learning plans in education that can help foster learner-centered education. The research implied that the individualized learning plans represent a concrete and straightforward way to individualize education and also foster the skills necessary for self-regulated lifelong learning.

Although many research studies on teachers' perceptions have been conducted, there is a shortage related to the EFLteachers' perceptions of the implementation of individualized learning model. Neither much research in this field is conducted in Vietnam nor in the region of the Mekong delta. For this reason, my research would be necessary to 
provide more understanding into the research topic and the findings will provide some valuable information for further research that relates to the individualized learning model in the region.

\section{Methodology}

This research was designed as a descriptive research which employed both quantitative and qualitative methods. Particularly, all of the participants were asked to respond to the 40-item-questionnaire. Particularly, the close-ended questions were designed in form of 5-point Likert scale and the results were reported with the Statistic Test of SPSS (Statistics Package for Social Science) such as mean, standard deviation, ectand were compared to One Sample T-Test or run with Descriptive Statistic Test. The resultswould help reveal the teachers' perceptions of the implementation of the individualized learning. Of equal importance, nine participants were then invited randomly for the interview. The semi-structured interview was used to gather qualitative data and provided more insightful understandings and interpretation of such learning model. The participants involved in the research are 18 Vietnamese teachers of English and eight foreign teachers from the English language center where the individualized learning model is implemented. All the participants pursued high education and professional development, they are bachelor and master degree holdersand others got Teachers of English to Speakers of Other Languages(TESOL). The participants were explained clearly about the purposes and information of the questionnaires as well as the interview before they started doing

\section{Results and Discussion}

\subsection{Teachers' perceptions of the implementation of the individualized learning}

Table 4.1: Summary ofteachers' perceptions of the implementation of the individualized learning

\begin{tabular}{lc}
\hline Teachers' perceptions of the implementation of the individualized learning & Mean \\
\hline 1. General perceptions of the ILM & 3.88 \\
2. Perceptions in planning the ILM & 3.83 \\
3. Perceptions in implementing the ILM & 3.66 \\
4. Perceptions in motivating the learners in the ILM & 4.11 \\
5. Perceptions in evaluating the learners in the ILM & 3.87 \\
\hline
\end{tabular}

$\mathrm{M}=\mathbf{3 . 8 4}$

Regarding to the teachers' general perceptions of the individualized learning, the results from the questionnaire supported the conclusion that the participants' general perceptions of the individualized learning affected two out of four elements including the participants' perceptions of implementing the individualized learning and the participants' perceptions of motivating learners in
First of all, the reliability was checked. The Cronbach's alpha was relatively high $(\alpha=.886)$, which means that the questionnaire was reliable. Therefore, the data could be analyzed with a Descriptive Statistic Test of SPSS to collect the average mean score of perceptions of the 26 teachers of the implementation of the individualized learning model. The results from questionnaires to teacher respondents are aimed to investigate the teachers' perception of the implementation of individualized learning model including: (1) teacher's general perceptions of the individualized learning; (2) theirs in planning the individualized learning; (3) theirs in implementing the individualized learning; (4) theirs in motivating the learners in the individualized learning; (5) theirs in evaluating learners in the individualized learning. In brief, the teachers' perceptions of the implementation of the individualized learning was just above average. (M= 3.8423). This conclusion is not in line with the hypotheses that the teachers' perceptions towards the individualized learning is somewhat high. The result is also different from the relevant studies mentioned in the literature review. In the study about the teachers' perceptions of efficacy about individualized instruction, Karadag (2010) determined that teachers perceived themselves moderately sufficient in terms of establishing objectives for learners; designing suitable teaching material in teaching-learning process; connecting new knowledge with learners' prior knowledge and; constructing the environment which helps students to realize their powerful and weak aspects.

Moreover, among the five components, the participants perceived much on motivating and evaluating the learners. Likewise, the implementation the individualized learning was not perceived highly. the individualized learning. Previous research has shown that the positive effects of teaching method on the individualization of the educational process manifests itself in the increased motivation for learning as well as in greater learner autonomy if compared to conventional teaching methods (Frunză and Petre, 2015). This suggests that when the teachers understood their roles in the individualized 
learning clearly, they would know how to implement such learning model effectively and motivate their learners positively. The same logic underlines that the teachers' perceptions of motivating learners in the individualized learning with the highest mean score $(M=4.1154)$. When the teachers help their learners improve motivation, that learner would become a kind of partner. They then actively engage in the course, rather than a passive, just show up kind of class. This active engagement leads to a more adaptive learning mentality that can better prepare learners for future learning and careers.

4.2 The advantages and disadvantages teachers face when the individualized learning is implemented in their classroom

By recognizing the teacher's level of perceptions, the researcher wants to get more insight into their implementation of the individualized learning. As a result, there were four main advantages from implementing the individualized learning related to the flexibility of the learning pace, the material and the learning schedule; the instant supports from the teachers; the expansion of learners' confidence; and the enhancement of learners' scholarly performance were four main advantages. On the other hand, the results of the interview also revealed two main disadvantages from implementing the individualized learning as time-consuming and lacking of interaction between learner and learner.

The results of the interview reflected some salient features of the individualized learning. As what was demonstrated, it can be pointed out that flexibility was one of the greatest advantage of the individualized learning when four out of nine participants shared their similar agreements on this benefit. It is to go the right way with Baker and Goldberg (1973) that the individualized learning is a highly flexible model of multiple materials and procedure, in which the learner is given the substantial responsibility for planning and carrying out his own organized program of studies, with the assistance of his teacher and in which his progress is determined solely in terms of those plans.

Besides, Meyer and Faraday (2008) found some evidence of the benefits of individualized learning, including encouraging social incorporation by countering alienation. To state the matter differently, the results of the interview revealed that lacking of interaction between learners with each other could be named as a disadvantage of the individualized learning.

All things considered, despite the similarities among findings of the current research with other previous related studies, the current research provided some additional findings that had not been found in other research.

\section{Conclusion}

The result shows that the teachers' perceptions of the implementation of the individualized learning was high although the level of perceptions was not high. Consequently, they understood the individualized learning quite well and revealed that there were four main advantages from implementing the individualized learning related to the flexibility of the learning pace, the material and the learning schedule; the instant supports from the teachers; the expansion of learners' confidence; and the enhancement of learners' academic performance. On the other hand, the results of the interview also revealed two main disadvantages from implementing the individualized learning as time-consuming and lacking of interaction between learner and learner. The results contribute a better understanding of howteachers perceived the individualized learning modelwhen implementing it and provide more valuable information for further research that relates to such learning model in Mekong Delta region.

\section{Acknowledgements}

The authors would like to send a basketful of thanks to the teachers spending their priceless time participating in the study.

\section{Reference}

[1] Al Rifai, N. (2010). Attitude, Motivation, and Difficulties Involved in Learning the English Language and Factors that Affect Motivation in Learning It. Procedia-Social and Behavioral Sciences, 2(2), 5216-5227.

[2] Allen, I. E., \& Seaman, C. A. (2007). Likert Scales and Data Analyses. Quality progress, 40(7), 64.

[3] Baker, G. L., \& Goldberg, I. (1973). The Individualized Learning System: What It Is and How To Use It. Individualized Instruction--programs and Materials: Selected Readings and Bibliography, 61.

[4] Bamberger, M. (2012). Introduction to Mixed Methods in Impact Evaluation. Impact Evaluation Notes, 3, 1-38.

[5] Bloom, T., \&Kissane, E. (2011). Individual Learning Plans: Improving Learner Performance.

[6] Bray, B., \&McClaskey, K. (2012). Personalization vs Differentiation vs Individualization. Dostopnona:

http://education.

ky.gov/school/innov/Documents/BB-KM-

Personalizedlearningchart-2012. pdf. 
[7] Burns, M. (2015, May 19). The College Puzzle. A college success blog by Dr. Michael W. Kirst. Retrieved February 06, 2018, from

https://collegepuzzle.stanford.edu/tips-forcollege-educators-how-to-hold-learnersattention/

[8] Dornyei, Z. (2001). Teaching and Researching Motivation. Harlow, England: Longman.

[9] Dowsett, G. (1986). Interaction in the Semistructured Interview. In M. Emery (ed.), Qualitative research (50-56). Canberra: Australian Association of Adult Education.

[10] Duong, H. T. (2012, February 22). LễCôngBố "PhươngPhápGiảngDạy\&HọcTập Active Learning". Retrieved December 12, 2017, from http://ama.edu.vn/tin-tuc/le-cong-bophuong-phap-giang-day-hoc-tap-activelearning/

[11] Efron, R. (1969). What is Perception?. In Proceedings of the Boston Colloquium for the Philosophy of Science 1966/1968. Springer, Dordrecht. 137-173

[12] Fletcher, J. D. (1992]. Individualized Systems of Instruction. In M .C .Alkin (Ed.], Encyclopedia of Educational Research (pp. B13-B18]. New York: Macmillan

[13] Frunză, V., \&Petre, C. (2015).Obstacles in Learning's Differentiation

and Individualization on Primary School. ProcediaSocial and Behavioral Sciences, Vol ume 180, 573-579

[14] Gardner, R.C., Lalonde, R.N. (1984) Investigating a Causal Model of Second Language Acquisition: Where Does Personality Fit? Canadian Journal of Behavioural Sciences, 16 (3), 224-234.

[15] Handricks. (2017, October 5). Advantages \& Disadvantages of Classroom Learning. Retrieved October 9, 2017, from http://classroom.synonym.com/advantagesdisadvantages-classroom-learning7922444.html

[16] Harackiewicz, J. M., \&Sansone, C. (2000). Rewarding competence: The importance of goals in the study of intrinsic motivation. Intrinsic and extrinsic motivation: The search for optimal motivation and performance, 79-103.

[17] Highland, C. (2015). Self-paced Individualized Learning(Doctoral dissertation, University of Wisconsin-River Falls).

\section{ISSN 2455-6378}

[18] Howton, R. (2017, June 18). Turn your Classroom into a Personalized Learning Environment. Retrieved February 20, 2018, from https://www.iste.org/explore/articleDetail?arti cleid $=416$

[19] Hubbard, R. (2012, October 03). What Is Goal-Based Learning? Retrieved January 27, 2018, from https://robhubbard.wordpress.com/2012/10/0 3/what-is-goal-based-learning/

[20] Jones, C. A. (2005). Assessment for Learning. Learning and Skills Development Agency, [Online] Available at: http://dera.ioe.ac.uk/7800/1/Assessmentfor Learning.pdf

[21] Karadag, R. (2010). Teachers' Efficacy Perceptions about Individualized Instruction. Online Submission, 8.

[22] King, L. (2013, September). Individualized Instruction: Definition \& Example. Retrieved January 26, 2018, from https://study.com/academy/lesson/ individualized-instruction-definitionexample.html

[23] Latchanna, G. \&Dagnew, A. (June 2009). Attitude of Teachers towards the Use of Active Learning Methods. E-journal of All India Association for Educational Research, 21(1),

http://www.ejournal.aiaer.net/vol21109/12.\% 20Latchana\% 20\&\%20Dagnew.pdf

[24] Little, J. W. (1991). Organizing School for Teacher Learning. In G. Skyes\& L. DarlingHammond (Eds.), Teaching as learning profession: Handbook of policy and practice, 233-267.

[25] Lockspeiser, T. M., \&Kaul, P. (2016). Using Individualized Learning Plans to Facilitate Learner-Centered Teaching. Journal of pediatric and adolescent gynecology, 29(3), 214-217.

[26] Meyer, B., Haywood, N., Sachdev, D., \& Faraday, S. (2008). What Is Independent Learning And What Are the Benefits for Pupils?. Department for Education publication. Retrieved May, 28, 2011.Crystal, D. (2012). English as a global language: Cambridge university press.

[27] Nunan, D. (1993). From LearningCenteredness to LearnerCenteredness. Applied Language Learning, 4, $1-18$. 
[28] Paschler, H., McDaniel, M., Rohrer, D., and Bjork, R. 2010. Learning styles: Concepts and evidence. Psychological Science in the Public Interest 9, 105-119.

[29] Peters, A. (2015). Incorporating Multiple Intelligences Theory into English Classes. World Scientific News, 17, 1-63.

[30] Powney, J. \& M. Watts (1984) "Reporting interviews: a code of good practice." In Research Intelligence.

[31] Russel, B. H., \& Ryan, G. W. (2003). Techniques to identify themes in qualitative data. Field Methods, 15(1), 85-109.

[32] Ryan, R. M., \& Deci, E. L. (2000).

Self-determination theory and the facilitation of intrinsic motivation, social development, and well-being. American Psychologist, 55, 68-78.
[33] Schargel, F. P., \&Smink, J. (2001). Strategies to Help Solve our School Dropout Problem. Larchmont, NY: Eye on Education.

[34] Takac, V.P. (2008) Vocabulary learning strategies and foreign language acquisition. Clevedon, UK: Multilingual Matters.

[35] Webb, L. L., \& Howard, T. E. (1977). Individualized Learning: An Achievable Goal for All!. Educational Leadership, 34(5), 356360 .

[36] Wile, E. (2007). Factors That Affect Individual Learning. Retrieved February 02, 2018, from http://classroom.synonym.com/factors-affectindividual-learning-8207913.html

[37] Zimmerman, B. J. (1989). A Social Cognitive View of Self-Regulated Academic Learning. Journal of educational psychology, 81(3), 329 